\title{
Growth Performance of Transgenic Mud Loach Misgurnus mizolepis Carrying a GH Transgene Driven by Mud Loach C-Type Lectin Regulator
}

\author{
Ha Yeon Song and Dong Soo Kim* \\ Department of Marine Bio-Materials and Aquaculture, Pukyong National University, Busan 608-737, Korea
}

\begin{abstract}
Growth hormone (GH) transgenesis in fish has the potential to improve aquaculture efficiency and capacity. However, many fastgrowing transgenic fish have experienced side effects caused by excess GH expression. To overcome this unwanted issue associated with several GH transgenic mud loach Misgurnus mizolepis lines carrying GH construct driven by a strong $\beta$-actin regulator (pml $\beta$-actGH), we performed an alternative version of GH autotransgenesis using a weaker but more stable regulator, the mud loach lectin promoter. GH transgenesis with a pmlectGH construct consisting of the mud loach GH gene driven by the 2.3-kb lectin promoter exhibited significant growth stimulation. However, the extent of the growth acceleration in pmlectGH transgenics (six times maximum when assessed 2 months post hatching) was much less than that in transgenic individuals carrying the pml $\beta$-actGH construct. Additionally, the extraordinary gigantism that was common in pml $\beta$-actGH-transgenic mud loaches was diminished in transgenic loaches harboring the pmlectGH construct. Transgenic founders (pmlectGH) successfully transmitted their transgene into the next generation with up to $41 \%$ frequency. Growth stimulation also persisted in the transgenic F1 strains, with a seven-fold increase in maximum body weight at 6 months of age.
\end{abstract}

Key words: Misgurnus mizolepis, Transgenic mud loach, Lectin regulator, GH-transgenesis

\section{Introduction}

Transgenic fish technology not only provides a unique model system for studying gene regulation in vertebrates but also offers a method to increase the efficiency of farming of many aquaculture-relevant species (Kapuscinski, 2005). In the last two decades, a number of fish species of diverse taxonomic groups have been subject to transgenic manipulation. Most transgenic studies on commercially important fish species have focused on growth enhancement by growth hormone (GH) transgenesis (Nam et al., 2007).

Many post mortem studies that reported significant growth responses to $\mathrm{GH}$ transgenesis have used strong or ubiquitous regulators such as $\beta$-actin (Nam et al., 2001) or metallothionein (Devlin et al., 1994, 2004) promoters. However, in spite of these successful demonstrations, strong expression of $\mathrm{GH}$ may cause additional unwanted side effects in some proportion of transgenic individuals. These side effects include malformed vertebrae, acromegaly and unnecessary gigantism; all are unfavorable for the practical application of the transgenics to aquaculture (Devlin et al., 1995; Nam et al., 2002).

Mud loach Misgurnus mizolepis has many merits as a model system for transgenic studies, such as fast and transparent embryonic development, short generation time, year-round multiple spawning under controlled conditions, and relatively well-established techniques for genetic manipulation (Nam, 2005). Growth of this species is readily accelerated through $\mathrm{GH}$ transgenesis using a transgene construct consisting of the
Open Access http://dx.doi.org/10.5657/FAS.2012.0043

This is an Open Access article distributed under the terms of the Creative Commons Attribution Non-Commercial License (http://creativecommons. org/licenses/by-nc/3.0/) which permits unrestricted non-commercial use, distribution, and reproduction in any medium, provided the original work is properly cited. pISSN: 2234-1749 eISSN: 2234-1757
Received 5 September 2011; Revised 8 November 2011; Accepted 29 November 2011

*Corresponding Author

E-mail: dongskim@pknu.ac.kr 
mud loach $\beta$-actin promoter and the $\mathrm{GH}$ gene (pml $\beta$-actGH). However, several transgenic strains harboring the pml $\beta$-actGH construct suffer from abnormal physiology and morphology (Nam et al., 2002). As such, development of GH transgenesis with greater stability became the objective of this study. Therefore, we tested the growth response of mud loach to an alternative $\mathrm{GH}$ autotransgenesis using a potentially weaker regulator, the mud loach lectin promoter.

\section{Materials and Methods}

\section{Generation of GH construct driven by the lectin promoter}

A mud loach genomic DNA library was screened with a probe, the DIG-labeled mud loach liver EST clone, which encoded mud loach hepatic C-type lectin. Multiple positive clones from the filter hybridization were analyzed by restriction mapping and shot-gun sequencing. Based on this sequence analysis, the $5^{\prime}$-upstream sequence of the mud loach C-type lectin gene was characterized using several web-based bioinformatic tools. A 2.3-kb upstream fragment from the ATG start codon of the lectin gene was isolated by PCR using the primers mlectP-F (5'-AAGAGTGTGGCTTTGACCC-3') and mlectP-R (5'-GGAAAAGTGACACATCTGC-3'), and a DNA template (500 ng) was prepared from the identified phage clone containing the mud loach lectin gene. PCR amplification was carried out as follows: 30 cycles of $94^{\circ} \mathrm{C}$ for $1 \mathrm{~min}, 60^{\circ} \mathrm{C}$ for $30 \mathrm{~s}$, and $72^{\circ} \mathrm{C}$ for $1.5 \mathrm{~min}$, with an initial denaturation step at $94^{\circ} \mathrm{C}$ for $2 \mathrm{~min}$. The PCR product was cloned into the pGEM-T Easy Vector (Promega, Madison, WI, USA), and recombinant clones with the correct insert size were sequenced in both directions. The lectin promoter was spliced from the pGEM-T Easy Vector plasmid using SacII and SpeI restriction endonucleases and inserted into the same restriction sites upstream of the mud loach GH gene in the pBluescript II KS phagemid vector (Stratagene, La Jolla, CA, USA). Configuration of the 7.4-kb pmlectGH transgene was confirmed by restriction mapping and sequencing.

\section{Gamete collection and microinjection}

Mature mud loach female and male brood fish were given an intraperitoneal injection of human chorionic gonadotropin at the doses of $10 \mathrm{IU}$ and $2 \mathrm{IU}$ per gram body weight, respectively (Kim et al., 1994). Eggs were artificially inseminated with sperm using the wet method, and the resultant embryos were held at $8^{\circ} \mathrm{C}$ until used for microinjection. Microinjection was carried out into one-celled embryos with $100 \mu \mathrm{g} / \mathrm{mL}$ pmlectGH in buffer (10 mM Tris-Cl, $\mathrm{pH} 8.0 ; 0.1 \mathrm{mM}$ EDTA, $\mathrm{pH}$ 8.0; $0.05 \%$ phenol red) (Nam et al., 1999). After microinjection, the embryos were transferred to a well-aerated incubator at $25 \pm 1^{\circ} \mathrm{C}$ until hatching. Hatching success and early surviv- al rate up to yolk sac absorption were estimated as percentages of eggs injected and larvae hatched, respectively, based on triplicate examinations using at least 110 embryos randomly chosen from each replicate batch. To prepare the positive control for GH transgenesis, pml $\beta$-actGH, which had been previously used for generating GH-transgenic mud loach (Nam et al., 2001), was microinjected into another batch of embryos, and the non-injected embryos were used as negative controls.

\section{Body-weight frequency distribution, PCR typing, and founder growth trial}

After hatching, 24 larvae from each injected batch were subjected to PCR amplification of the transgene to confirm successful transfer. DNA was prepared from whole body of larvae using a conventional sodium dodecyl sulfate/proteinase $\mathrm{K}$ method. PCR was carried out using a pair of primers designed to amplify the junction fragment between the regulator and the structural $\mathrm{GH}$ gene for each transgene construct. Oligonucleotide primers were mlectP-1F (5'-GTTATGGAGTCCCTCCCAA-3') and mlGH-1R (5'-CAGCCAGCTGGTGCAGGTG-3') for the pmlectGH construct, and ml $\beta$-actP-1F (5'-CCACGCGCTGAATCGGCGGC-3') and $\mathrm{mlGH}-1 \mathrm{R}$ (see above) for the pml $\beta$-actGH transgene. Reactions consisted of 30 cycles of $94^{\circ} \mathrm{C}$ for $1 \mathrm{~min}, 58^{\circ} \mathrm{C}$ for 1 $\mathrm{min}$, and $72^{\circ} \mathrm{C}$ for $1.5 \mathrm{~min}$, with an initial denaturation step at $94^{\circ} \mathrm{C}$ for $2 \mathrm{~min}$. After confirmation of the successful transgene delivery to a portion of microinjected embryos, the remaining larvae in each group were reared at $25^{\circ} \mathrm{C}$ in three separate tanks (50 L each for the pmlectGH-injected, pml $\beta$-actGH-injected, and non-injected groups) until 1 week of age. Fish were then transferred to one of three larger tanks $(120 \mathrm{~L})$ for 2 months' further growth. Fish were fed a commercial carp diet on an ad libitum basis during the experimental period. At 2 months, the body weight (nearest $1 \mathrm{mg}$ ) of each individual was determined to evaluate the body-weight frequency distribution. The presumed transgenic founders with large body size were identified by PCR screening using the DNA template prepared from a caudal fin clip (Nam et al., 2003). PCR primers were as described above. Transgenic founder fish (PCR-positive for pmlectGH) were selected and grown to sexual maturity to be tested for germ-line transmission to the F1 generation.

\section{Germ-line transmission and growth characteristics of F1 progeny}

Seven founder pmlectGH-transgenic males were crossed with normal mud loach females to produce F1 progeny. Artificial insemination was performed as described previously (Nam et al., 2001), and fertilization rate, hatching success, and early survival up to yolk sac absorption were examined as above. At least 48 randomly chosen larvae (3 days old) from each cross were screened by PCR amplification of the transgene, as described above, to determine the germ-line trans- 
mission frequency. At one month, fast-growing transgenic F1 individuals were again identified by PCR and subjected to a growth trial up to 6 months of age. Growth performances of transgenic progeny $(n=22)$ from each of four families were tested in 200-L tanks along with their non-transgenic siblings. Body weights were assessed every month. Fish were fed with commercial carp feed, and water temperature was maintained at $25 \pm 1^{\circ} \mathrm{C}$. Differences in body weights were assessed by ANOVA followed by Duncan's multiple-range test at $P=0.05$.

\section{Results and Discussion}

\section{Viability of microinjected embryos and efficiency of gene transfer}

Non-injected control groups showed fairly good hatching success and early survival, whereas the microinjected groups revealed significantly reduced scores in both hatching success ( $29.8 \%$ for $\mathrm{pml} \beta$-actGH and $21.5 \%$ for pmlectGH) and percent early survival up to yolk sac absorption (61.8 and 68.5\% for pml $\beta$-actGH- and pmlectGH-injected groups, respectively) (Table 1). The lower viability of microinjected embryos was not surprising, as many previous studies have reported similar observations (Pandian and Marian, 1994; Gong et al., 2007). The adverse effects of microinjection on embryo viability are usually species specific. This harmful effect on viability arises from mechanical damage to the chorion and egg membrane during microinjection rather than from the exogenous DNA itself (Pandian and Marian, 1994). The incidence of transgene presence in 1-week-old fry from each microinjected group (38\% for pmlectGH group and $29 \%$ for pml $\beta$-actGH) was higher than those previously reported (see Nam et al., 2007). However, the presence of extrachromosomal persistent transgene copies might also be, at least in part, responsible for such a high incidence. Exogenously introduced DNA usually undergoes formation of multiple concatemers, which frequently persist not only in early embryos but also in adults for a long period (Nam et al., 1999; Kim et al., 2004; Gong et al., 2007).

Table 1. Hatching success, early survival up to yolk sac absorption and incidence of transgene in microinjected and non-injected control groups of mud loach Misgurnus mizolepis

\begin{tabular}{|c|c|c|c|}
\hline Group & $\begin{array}{c}\text { Hatching } \\
\text { success (\%) }\end{array}$ & $\begin{array}{c}\text { Early survival } \\
\text { rate }(\%)^{\dagger}\end{array}$ & $\begin{array}{c}\text { Incidence of } \\
\text { transgene }(\%)^{*}\end{array}$ \\
\hline Non-injected & $81.5 \pm 5.5^{b}$ & $82.3 \pm 4.1^{b}$ & - \\
\hline pml $\beta$-actGH-injected & $29.8 \pm 4.6^{\mathrm{a}}$ & $61.8 \pm 5.5^{\mathrm{a}}$ & 29 \\
\hline pmlectGH-injected & $21.5 \pm 3.9^{\mathrm{a}}$ & $68.8 \pm 6.7^{\mathrm{a}}$ & 38 \\
\hline
\end{tabular}

Mean \pm SDs (from triplicate examinations) with same letters were not statistically different based on ANOVA $(P>0.05)$.

*Percentage of embryos taken at 24 hours post-fertilization, ${ }^{\dagger}$ Percentage of hatched larvae, ${ }^{\ddagger}$ Based on PCR assay using 24 randomly chosen hatched larvae.

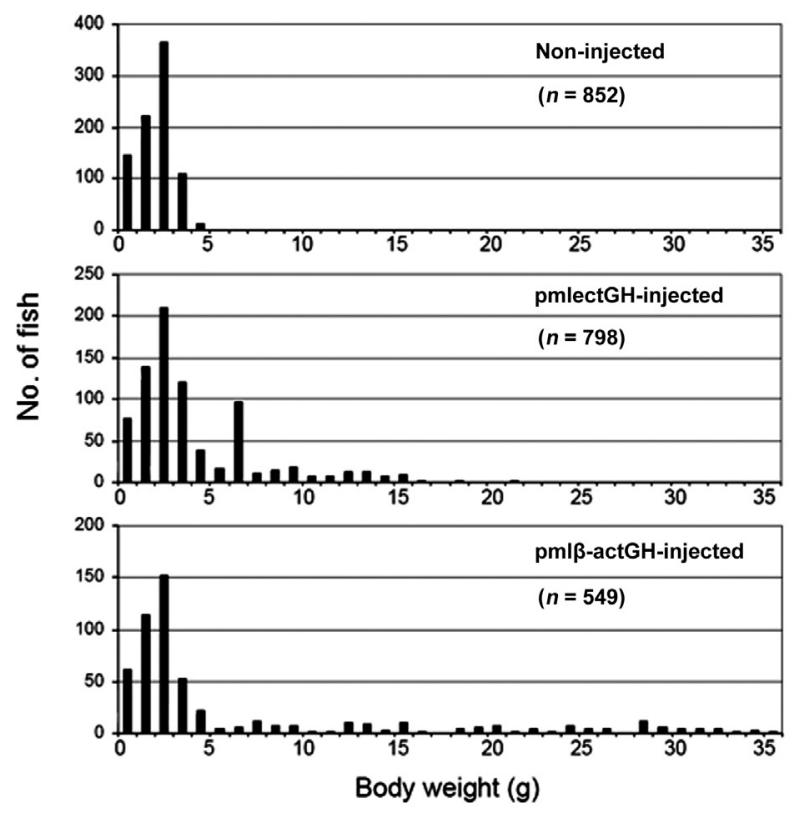

Fig. 1. Frequency distribution of body weights for pmlectGH- and pml $\beta$-actGH-injected groups along with non-injected control group of mud loach Misgurnus mizolepis as assessed at 2 months post hatching.

\section{Body-weight frequency distribution}

The body-weight frequency in non-injected controls at 2 months showed a normal distribution with a mean of $2.6 \mathrm{~g}$ (Fig. 1). The group injected with pml $\beta$-actGH also displayed a normal distribution, but many individuals deviated from this, as expected (see also Nam et al., 2001). Of the 549 individuals that developed from embryos injected with pml $\beta$-actGH construct, 138 presumed transgenic founders exhibited significantly heavier body weights than those of individuals belonging to the largest class in the non-injected control group. More importantly, a number of pml $\beta$-actGH transgenics showed extraordinarily heavy weights, more than 10 times the average body weight of the control group; the largest transgenic individuals reached $36 \mathrm{~g}$. Meanwhile, many individuals in the pmlectGH-injected group $(n=798)$ were also large, with body weights clearly above the average for the non-injected group. However, the number of such large fish (103 individuals heavier than the largest control fish) was smaller than that in the pml $\beta$-actGH-injected group. Furthermore, their body weights were not as high as those of the pml $\beta$-actGH transgenics. The body-weight distribution in the pmlectGH-injected group was narrower than that in the pml $\beta$-actGH-injected group. Only a few presumed transgenic individuals displayed body weights greater than $15 \mathrm{~g}$, and most fast-growing fish carrying pmlectGH were less than six-fold heavier than the non-injected group (Fig. 1).

PCR screening suggested that most, but not all, such large individuals contained the corresponding transgene constructs 
in their fin tissues (PCR gels not shown). However, several individuals were unexpectedly PCR negative despite their extraordinarily large body sizes. This might be explained by a mosaic transgene distribution across tissues, as we tested only fin tissue (Rahman and Maclean, 1999; Dunham, 2004). Although constructs were introduced into one-celled embryos, transgenes may have been integrated into host chromosomes after several rounds of cell division, leading to an extremely high level of mosaicism in these individuals. The late integration of transgenes into fish genomes has often been observed, especially when the DNA was introduced by microinjection (Iyengar et al., 1996). Further examination based on PCR assays of diverse tissues is needed to determine whether such individuals are true transgenic founders harboring transgene constructs. In spite of these questionable individuals, it was evident that the early growth responses of transgenic mud loaches to both GH constructs differed substantially. The effect of pmlectGH transgenesis on growth stimulation in transgenic mud loach was more moderate than that of pml $\beta$-actGH transgenesis.

\section{Germ-line transmission frequency}

Of seven putative transgenic male founders, only five transmitted their transgene construct to the next generation. Fertilization rates, hatching success, and survival up to yolk sac absorption were similar in all families, including the nontransgenic control cross $(P>0.05)$ (Table 2). This indicates that the absence of transgenic progeny in the two families showing no germ-line transmission was not caused by adverse effects of pmlectGH transgenesis on embryonic development and early ontogenesis. The germ-line transmission frequency was variable, ranging from 26 to $42 \%$ on average (Table 2). Hence, with the exception of transgenic founder \#110, which exhibited a transgene frequency of $42 \%$, all founders (possibly not even male \#110) were likely mosaic at the transgene locus, which is a common feature of transgenic founder fish (Nam et al., 2007). Although several reports have claimed that co-in-

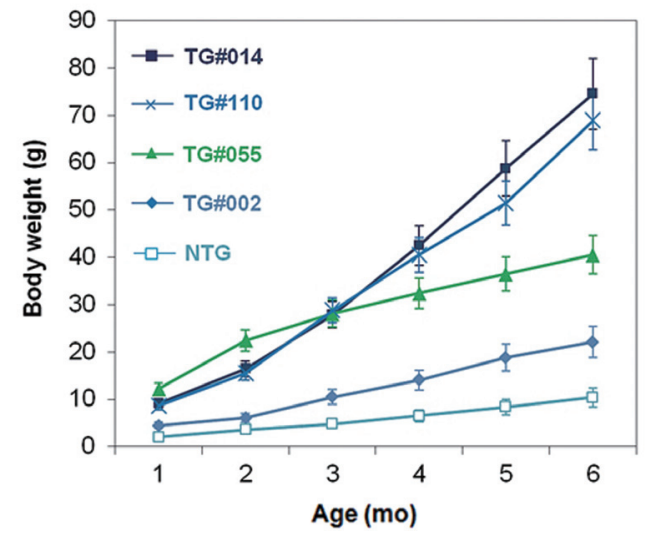

Fig. 2. Growth characteristics of F1pmlectGH-transgenic lines of mud loach Misgurnus mizolepis with function of age up to 6 months. Vertical bars indicate standard deviations. Transgenic F1 lines TG\#002 ( ), TG\#014 $(\mathbf{- )}$, TG\#055 ( $\mathbf{\Delta})$ and TG\#110 ( $\times$ ) were named after the identification codes for transgenic founder males (see Table 2) and non-transgenic is denoted as NTG ( $\square)$. Statistical separations of means at 6 months were TG\#014/\#110, TG\#055, TG\#002 and NTG based on ANOVA $(P<0.05)$.

jection of meganuclease (I-Scel) might resolve most problems associated with microinjection-based transgenesis (Thermes et al., 2002; Grabher et al., 2004), the compatibility of this technique should be validated in other fish species.

\section{Growth characteristics of F1 progeny}

Growth stimulation of pmlectGH transgenics was also reproducible in the F1 generation. Transgenic F1 lines showed strain-dependent growth stimulation, ranging from two- to seven-fold increases in body weight relative to that of nontransgenic siblings when assessed at 6 months of age (Fig. 2). Strain-specific growth patterns were also found. For example, transgenic line TG\#055 showed the fastest early growth, but later stabilized. In contrast, TG\#014 showed a consistent slope of the growth curve until the end of the growth trial. Transgene-based growth stimulation in fish is governed by a num-

Table 2. Germ-line transmission of pmlectGH transgene from founder transgenic males to F1 progeny of mud loach Misgurnus mizolepis

\begin{tabular}{lcccc}
\hline Experimental male & $\begin{array}{c}\text { Fertilization rate } \\
(\mathbf{\%})\end{array}$ & $\begin{array}{c}\text { Hatching success } \\
\mathbf{( \% )}\end{array}$ & $\begin{array}{c}\text { Early survival } \\
(\mathbf{\%})\end{array}$ & $\begin{array}{c}\text { Incidence of transgene } \\
(\mathbf{\%}))^{*}\end{array}$ \\
\hline Non-transgenic male & $91.4 \pm 4.2$ & $85.1 \pm 5.8$ & $82.1 \pm 4.4$ & - \\
Transgenic male \#002 & $93.5 \pm 5.0$ & $84.3 \pm 2.8$ & $84.1 \pm 5.8$ & 27 \\
Transgenic male \#014 & $89.2 \pm 4.4$ & $83.4 \pm 5.4$ & $88.0 \pm 3.4$ & 38 \\
Transgenic male \#055 & $92.3 \pm 3.4$ & $90.1 \pm 5.0$ & $82.5 \pm 4.8$ & 32 \\
Transgenic male \#081 & $92.1 \pm 5.1$ & $88.5 \pm 6.4$ & $85.4 \pm 5.5$ & 0 \\
Transgenic male \#101 & $90.5 \pm 4.4$ & $89.1 \pm 3.6$ & $84.9 \pm 6.3$ & 0 \\
Transgenic male \#110 & $94.1 \pm 3.1$ & $89.4 \pm 2.8$ & $90.1 \pm 4.4$ & 42 \\
Transgenic male \#133 & $90.4 \pm 4.9$ & $86.6 \pm 6.1$ & $91.4 \pm 5.3$ & 26 \\
\hline
\end{tabular}

There was no statistical difference in fertilization, hatching and early survival among lines including non-transgenic cross based on ANOVA $(P>0.05)$.

"Based on PCR screening using at least 48 larvae from each cross. 
ber of factors associated with transgenic status, such as transgene copy number, transgene integration site, and the fashion of GH expression (Rahman et al., 2000; Devlin et al., 2004), which will therefore be key subjects in future studies with these transgenic lines. Although we have not yet quantitated $\mathrm{GH}$ transcript and protein levels, it is generally agreed that the lectin regulator is weaker than the previously used $\beta$-actin promoter in terms of moderate growth stimulation across two generations. Unlike pml $\beta$-actGH transgenics that exhibited a greater than 35-fold growth acceleration (Nam et al., 2001, 2007), GH transgenesis driven by the lectin regulator resulted in maximum six- to seven-fold growth stimulation, even for the transgenic hemizygous genotype. Furthermore, the severe abnormalities caused by excess GH observed in several pml $\beta$ actGH transgenics was not noted in transgenic individuals harboring the pmlectGH construct. Furthermore, gigantism, a phenomenon typical of pml $\beta$-actGH transgenics, was diminished in pmlectGH transgenesis (Nam et al., 2001); the body size of most fast-growing pmlectGH transgenics was not greater than the normal body size of this species (maximum $\sim 100$ g under laboratory conditions).

In summary, GH transgenesis using a lectin regulator in an autotransgenic manner was performed in mud loach and resulted in growth improvement and germ-line transmission. The growth characteristics of pmlectGH transgenics were different from the pattern observed in the pml $\beta$-actGH construct: growth stimulation of pmlectGH transgenics was more moderate and stable; no severe abnormalities or extraordinary gigantism occurred. These data thus provide a good basis for the practical application of GH-transgenic mud loaches to aquaculture.

\section{Acknowledgments}

This study was supported by a research fund from the Ministry of Land, Transport and Maritime Affairs, Republic of Korea (Project \#20088033-1).

\section{References}

Devlin RH, Yesaki TY, Biagi CA, Donaldson EM, Swanson P and Chan WK. 1994. Extraordinary salmon growth. Nature 371, 209-210.

Devlin RH, Yesaki YT, Donaldson EM, Du SJ and Hew CL. 1995. Production of germline transgenic Pacific salmonids with dramatically increased growth performance. Can J Fish Aquat Sci 52, 13761384.

Devlin RH, Biagi CA and Yesaki TY. 2004. Growth, viability and genetic characteristics of GH transgenic coho salmon strains. Aquaculture 236, 607-632.

Dunham RA. 2004. Aquaculture and Fisheries Biotechnology: Genetic Approaches. CABI Publishing, Oxford, GB.

Gong Z, Maclean N, Devlin RH, Martinez R, Omitogun O and Estrada
MP. 2007. Gene construct and expression: information relevant for risk assessment and management. In: Environment Risk Assessment of Genetically Modified Organisms. Vol. 3. Methods for Transgenic Fish. Kapuscinski AR, Hayes KR, Li S and Dana G, eds. CABI Publishing, Oxford, GB, pp. 95-111.

Grabher C, Joly JS and Wittbrodt J. 2004. Highly efficient zebrafish transgenesis mediated by the meganuclease I-SceI. Methods Cell Biol 77, 381-401.

Iyengar A, Müller F and Maclean N. 1996. Regulation and expression of transgenes in fish: a review. Transgenic Res 5, 147-166.

Kapuscinski AR. 2005. Current scientific understanding of the environmental biosafety of transgenic fish and shellfish. Rev Sci Tech Off Int Epizoot 24, 309-322.

Kim DS, Jo JY and Lee TY. 1994. Induction of triploidy in mud loach (Misgurnus mizolepis) and its effect on gonad development and growth. Aquaculture 120, 263-270.

Kim DS, Kim BS, Lee SJ, Park IS and Nam YK. 2004. Comparative analysis of inherited patterns of the transgene in transgenic mud loach Misgurnus mizolepis lines carrying the CAT reporter gene. Fish Sci 70, 201-210.

Nam YK. 2005. Tailoring fish genome and transgenic manipulation as exemplified by mud loach (Misgurnus mizolepis). Fish Genet Breed Sci 35, 113-119.

Nam YK, Noh CH and Kim DS. 1999. Transmission and expression of an integrated reporter construct in three generations of transgenic mud loach (Misgurnus mizolepis). Aquaculture 172, 229-245.

Nam YK, Noh JK, Cho YS, Cho HJ, Cho KN, Kim CG and Kim DS. 2001. Dramatically accelerated growth and extraordinary gigantism of transgenic mud loach Misgurnus mizolepis. Transgenic Res 10, 353-362.

Nam YK, Cho YS, Cho HJ and Kim DS. 2002. Accelerated growth performance and stable germ-line transmission in androgenetically derived homozygous transgenic mud loach, Misgurnus mizolepis. Aquaculture 209, 257-270.

Nam YK, Park JE, Kim KK and Kim DS. 2003. A rapid and simple PCR-based method for analysis of transgenic fish using a restricted amount of fin tissue. Transgenic Res 12, 523-525.

Nam YK, Maclean N, Fu C, Pandian TJ and Eguia MRR. 2007. Development of transgenic fish: scientific background. In: Environment Risk Assessment of Genetically Modified Organisms. Vol. 3. Methodologies for Transgenic Fish. Kapuscinski AR, Hayes KR, Li S and Dana G, eds. CABI Publishing, Oxford, GB, pp. 61-94.

Pandian TJ and Marian LA. 1994. Problems and prospects of transgenic fish production. Curr Sci 66, 635-649.

Rahman MA and Maclean N. 1999. Growth performance of transgenic tilapia containing an exogenous piscine growth hormone gene. Aquaculture 173, 333-346.

Rahman MA, Hwang GL, Razak SA, Sohm F and Maclean N. 2000. Copy number related transgene expression and mosaic somatic expression in hemizygous and homozygous transgenic tilapia (Oreochromis niloticus). Transgenic Res 9, 417-427.

Thermes V, Grabher C, Ristoratore F, Bourrat F, Choulika A, Wittbrodt J and Joly JS. 2002. I-SceI meganuclease mediates highly efficient transgenesis in fish. Mech Dev 118, 91-98. 